\title{
On the upper tropospheric formation and occurrence of high and thin cirrus clouds during anticyclonic poleward Rossby wave breaking events
}

\author{
By RONALD EIXMANN ${ }^{1}$, DIETER H.W. PETERS ${ }^{1 *}$, CHRISTOPH ZÜLICKE ${ }^{1}$, \\ MICHAEL GERDING ${ }^{1}$ and ANDREAS DÖRNBRACK ${ }^{2}, \quad{ }^{1}$ Leibniz-Institut für Atmosphärenphysik an \\ der Universität Rostock, Schlossstraße 6, D-18225 Ostseebad Kühlungsborn, Mecklenburg, Germany; ${ }^{2}$ Institut für \\ Physik der Atmosphäre, DLR Oberpfaffenhofen, Germany
}

(Manuscript received 15 April 2009; in final form 14 January 2010)

\begin{abstract}
Ground-based lidar measurements and balloon soundings were employed to examine the dynamical link between anticyclonic Rossby wave breaking and cirrus clouds from 13 to 15 February 2006. For this event, an air mass with low Ertel's potential vorticity appeared over Central Europe. In the tropopause region, this air mass was accompanied with both an area of extreme cold temperatures placed northeastward, and an area of high specific humidity, located southwestward. ECMWF analyses reveal a strong adiabatic northeastward and upward transport of water vapour within the warm conveyor belt on the western side of the ridge over Mecklenburg, Northern Germany. The backscatter lidar at Kühlungsborn $\left(54.1^{\circ} \mathrm{N}, 11.8^{\circ} \mathrm{E}\right)$ clearly identified cirrus clouds at between 9 and $11.4 \mathrm{~km}$ height. In the tropopause region high-vertical resolution radiosoundings showed layers of subsaturated water vapour over ice but with a relative humidity over ice $>80 \%$. Over Northern Germany radiosondes indicated anticyclonically rotating winds in agreement with backward trajectories of ECMWF analyses in the upper troposphere, which were accompanied by a relatively strong increase of the tropopause height on 14 February. Based on ECMWF data the strong link between the large-scale structure, updraft and ice water content was shown.
\end{abstract}

\section{Introduction}

Cirrus clouds in the upper troposphere impact the climate significantly due to changed radiative conditions (Zhang et al., 1999; Sassen and Campbell, 2001; Lynch et al., 2002). Based on satellite measurements and radiative transfer calculations, Chen et al. (2000) deduced a net warming due to optically thin cirrus clouds. However, recent studies, e.g. by Fusina et al. (2007), point out that the net radiative impact depends strongly on ice water content and ice crystal number concentration. Despite recent progress in understanding and modelling of the microphysical properties and of the radiative impact of cirrus clouds, less research is devoted to the dynamical linkage of the occurrence of natural and anthropogenic cirrus clouds (contrail cirrus) and the various weather systems. In the middle latitudes, the most striking cirrus cloud features are produced by upper air disturbances associated with Rossby waves. It is well known, that especially in anticyclonic, poleward and downstream Rossby wave breaking (RWB) events the tropopause height increases significantly

\footnotetext{
*Corresponding author.
}

e-mail: peters@iap-kborn.de

DOI: $10.1111 / \mathrm{j} .1600-0870.2010 .00437 . x$ up to about $12 \mathrm{~km}$ in winter time. Due to the high altitude of tropopause, the cold temperatures in that area may enable the cirrus cloud formation (e.g. Spichtinger et al., 2003).

The formation of cirrus cloud particles depends crucially on the ambient temperature and moisture distribution and the vertical motions in the upper troposphere. Cirrus clouds form when rising air masses cool adiabatically until the required supersaturation for ice formation is exceeded. The actual nucleation depends not exclusively on the thermodynamic structure of the upper troposphere but also on the presence of aerosols which influence the microphysical formation processes (for an introduction into the topic, see Peter et al., 2006 or the recent paper series by Spichtinger and Gierens, 2009a-c and Krämer et al. 2009, and references therein). The formation of ice crystals has two major pathways, namely heterogeneous nucleation and homogeneous freezing of aqueous solution droplets (e.g. Koop et al., 2000). The heterogeneous nucleation is a summary of collective term for different formation mechanisms (deposition freezing, immersion freezing, condensation freezing and contact freezing, e.g. Vali, 1985). The former one is most important for warm temperatures $(T>235 \mathrm{~K})$, but the homogeneous freezing is most important for the low temperature regime $(T<235 \mathrm{~K})$. A review of heterogeneous and homogeneous nucleation for 
cold cirrus clouds is given by DeMott et al. (2003) and Koop (2004). Homogeneous nucleation is dominant for cold cirrus clouds (Kaercher and Stroem, 2003), although it can be modified by heterogeneous nucleation (e.g. Gierens, 2003; Kaercher et al., 2007; Spichtinger and Gierens, 2009b). Both pathways of cirrus formation need high ice supersaturations (Gierens et al., 1999); however, for homogeneous freezing of aqueous solution droplets the relative humidity thresholds are higher as for heterogeneous nucleation, i.e. in the range about $140 \%<\mathrm{RHi}<$ $170 \%$. Ice crystals can fall into subsaturated air and can survive there for a longer time (with $\mathrm{RHi}>80 \%$ ), due to the quite long timescale for evaporation of ice crystals.

Here, we concentrate on high cirrus clouds, thus, homogeneous freezing of aqueous solution droplets is the most likely mechanism. For homogeneous nucleation, the cirrus cloud formation crucially depends on the atmospheric dynamics as the formed ice crystal number density is highly dependent on vertical velocity (Kaercher and Lohmann, 2002). Vertical motions in the upper troposphere occur on various spatial and temporal scales ranging from slow large-scale ascents, e.g. in so-called warm conveyer belts, to violent mesoscale updrafts in convective clouds.

In this paper, we examine the influence of Rossby wave evolution on the formation and occurrence of cirrus clouds over the North Atlantic-European region. In a case study, we focus on the anticyclonic part of a RWB event because high cirrus clouds are known to occur often in conjunction with high-pressure systems. This is done in order to explore the potential of a parametrization, which relates the appearance of high cirrus clouds to RWB events. The investigation of the dynamical link between the Rossby wave dynamics and the occurrence of cirrus clouds is the main focus of this study.

The synoptic-scale dynamics in upper troposphere and lower stratosphere of middle latitudes is closely associated with Rossby wave evolution including propagating Rossby wave trains and RWB. Zonal wave numbers range between 5 and 9 , and these waves have typical timescales between 2 and 6 days. Rossby waves are important for transport processes in the free atmosphere because they determine the meridional flux of heat, momentum, and of minor constituents. The so-called "life cycle" of Rossby waves has been observed to some extent in the real atmosphere (Randel and Stanford, 1985). Idealized model experiments by Simmons and Hoskins (1978, 1980), based on dry primitive equations for aqua-planets, reproduced this life cycle for a single zonal Rossby wave quite well. They distinguished two types of wave evolution: equatorward downstream and upstream depending on anticyclonic and cyclonic horizontal background shear, respectively. In an extended model study Thorncroft et al. (1993) showed the RWB difference in air mass trajectories by considering maps of Ertel's potential vorticity (EPV) (Ertel, 1942) of the upper troposphere and applied 'EPV thinking' to both life cycles explicitly. If some more zonal Rossby wave modes are taken into account we will call this complex phenomenon of wave breaking a RWB event. Nakamura and Plumb (1994) discussed the RWB process in curved background streams. Additionally they showed the dependence of up- and downstream breaking on the radius of background stream deformation.

In a study of four winter RWB events, Peters and Waugh (1996) found strong poleward breaking events, upstream (downstream)—called P1 (P2), in specific extratropical regions referred to confluent (diffluent) regions of the background stream. In a climatological winter study of ERA-40 re-analyzes the geographical distribution of RWB events was determined objectively showing preferred regions over North Atlantic/Europe (Gabriel and Peters, 2008). Rossby waves break poleward and downstream very often over Europe with a rate of $30 \%$ of winter days (Zülicke and Peters, 2007). Especially in the upper troposphere these RWB events influence the horizontal and vertical distribution of radiative active tracers like ozone or water vapour through a northeastward and upward transport on the western flank of the upper tropospheric anticyclone. The link of RWB events and ozone anomalies has been studied in many papers (e.g. James and Peters, 2002; Koch et al., 2005).

Water vapour is an important natural greenhouse gas (Flohn et al., 1992). The strong horizontal and vertical transport of latent heat by Rossby waves and the release due to the water (vapour) cycle in the atmosphere contributes mainly to the energy budget of the troposphere on all time scales. The water cycle is included in many feedback processes with Rossby waves. For instance, a positive radiative feedback was found if water vapour is transported by the warm conveyor belt into higher altitudes up to the upper troposphere in connection with zonal ozone anomalies (Kirchner and Peters, 2003). This would enhance the formation of cirrus clouds by homogenous nucleation if the air masses are cold enough. The idea of combining both a RWB index and the occurrence rate of cirrus for studying climatological aspects is advanced. In a first step and in a framework of a case study, we examine this possible link where detailed measurements with high temporal resolution are available.

There are only a few studies that relate the formation and occurrence of cirrus clouds to the associated weather regimes with RWB events. Spichtinger et al. (2005a) showed that the outflow region of warm conveyer belts associated with middle latitude cyclogenesis (or Rossby wave evolution) can induce ice supersatured regions in the upper troposphere. Immler et al. (2008) studied the formation and occurrence of thin cirrus and contrails on the basis of lidar and radiosonde observations over eastern Germany during the heat wave in summer 2003. In particular, cirrus clouds were found to occur ubiquitously in highpressure systems where their coverage was on average $67 \%$. A midlatitude cirrus cloud climatology over Utah, USA, by lidar measurements from 1986 to 1996 was used to establish a regional subset of cloud heights combined with radiosondes (Sassen and Campbell, 2001). By visual inspection a classification in different weather regimes was given, showing the link of high cirrus 
clouds in cold anticyclones. Using ground-based remote sensing data of a 6-yr period collected by cloud radar measurements over Oklahoma, USA, Mace et al. (2006) investigated the cirrus cloud occurrence as function of the large-scale circulation. In general they found that the large-scale vertical motion is ascending as well as descending when cirrus clouds are observed, what makes it unlikely to use this quantity as the sole input of a simple parametrization. Spichtinger et al. (2005b) discussed the evolution of an inertia-gravity wave inducing cirrus cloud formation by mesoscale updrafts during a late phase of a RWB event.

Satellite images in the infrared band allow for observations of the spatial distribution of cirrus clouds but the disadvantage is the estimate of their vertical distribution. An excellent observation method to detect vertical profiles of ice fields around the tropopause level is a ground-based upward-pointing backscatter lidar. The aerosol backscatter profiles give an exact measurement of the altitude and vertical extension of cirrus clouds. In addition, the aerosol depolarisation ratio provides information on their shapes, permitting the distinction between liquid and solid aerosols. With contemporaneous radiosonde measurements, high-vertical resolution information on the hydro- and thermodynamic structure of the atmosphere, including the relative humidity over ice, the temporal changes of height and sharpness of the tropopause, can be combined with lidar results.

This study focuses mainly on the regional occurrence of cirrus clouds during an anticyclonic poleward downstream RWB event in the upper troposphere over Mecklenburg, Northern Germany. During that RWB event, a measuring campaign deploying remote-sensing and in situ instruments was conducted on 13-15 February 2006. The radiosonde launches at Kühlungsborn $\left(54.1^{\circ} \mathrm{N}, 11.8^{\circ} \mathrm{E}\right)$ were supplemented by German weather service (DWD) operational soundings in Northern Germany. All radiosonde data we used represent high-vertical resolution measurements. The results of these measurements were compared with European Centre for Medium-Range Weather Forecast (ECMWF) data analyses, and completed with comprehensive trajectory analyses to deduce the origin of the sampled air masses.

The paper is organized as follows. After this introduction and after an overview of the applied methodology in Section 2, Section 3 presents the results from the case 1 study of February 2006. In Section 4 three other cases with analyzed RWB events during the period from 1997 to 2006 will be presented. These results serve as background to substantiate the hypothesis that during anticyclonic poleward RWB events in middle latitudes high and thin cirrus clouds are generated. The paper concludes with a discussion in Section 5 and a summary.

\section{Methodology}

The main case study was planned by searching DWD forecasts maps for poleward RWB events during winter 2005/2006. After the campaign, operational ECMWF analyses were used to depict the dynamical signature of breaking Rossby waves on selected isentropic levels. Here, a short overview of used lidar and radiosonde measurements is given followed by a brief description of the method of backward trajectory analyses.

\subsection{Lidar observation}

The aerosol backscatter measurements were performed with the Rayleigh/Mie/Raman lidar using a Nd:YAG laser of the Leibniz - Institute of Atmospheric Physics at Kühlungsborn. The system was described in more detail by Alpers et al. (1999). For tropospheric measurements the vertical resolution was $50 \mathrm{~m}$. Lidar measurements give exact information about altitude, vertical extension and classes of structure substances of cirrus clouds along the lidar measuring path. Three wavelengths $(355,532$ and $1064 \mathrm{~nm})$ were available. The backscatter signal at $532 \mathrm{~nm}$ wavelength was used to monitor the temporal evolution of cirrus clouds. Here, we present the aerosol backscatter ratio $R_{\lambda}=\left(\beta_{\mathrm{p}, \lambda}+\beta_{\mathrm{m}, \lambda}\right) / \beta_{\mathrm{m}, \lambda}$ at $\lambda=532 \mathrm{~nm}$, where $\beta_{\mathrm{p}, \lambda}$ is the aerosol backscatter coefficient and $\beta_{\mathrm{m}, \lambda}$ denotes the molecular backscatter coefficient at the wavelength $\lambda$. In addition, simultaneous depolarisation measurements at $532 \mathrm{~nm}$ were taken to differentiate between liquid water droplets and ice crystals. Here, the depolarisation ratio $\delta_{\mathrm{p}, \lambda}=\beta_{\mathrm{p}, \lambda, \perp} / \beta_{\mathrm{p}, \lambda, \|}$ provides the particles' asphericity.

\subsection{Radiosounding}

On 14 February 2006 we launched radiosondes of type RS 92 (from VÄISÄLÄ, Finland) at Kühlungsborn $\left(54.1^{\circ} \mathrm{N}, 11.8^{\circ} \mathrm{E}\right)$. Further, at four DWD stations radiosondes were launched in the surrounding of Kühlungsborn in Northern Germany. Emden, Schleswig, Greifswald and Lindenberg are a part of the radiosonde net (maps of location, please see: www.dwd.de). At Kühlungsborn the time interval between radiosonde starts was about $2 \mathrm{~h}$, the vertical resolution was about $10 \mathrm{~m}$. Radiosonde data from the other stations are available for about 11:00 and 23:00 UT with about $50 \mathrm{~m}$ vertical resolution.

The measured meteorological parameters are temperature $T$, air pressure $p$, relative humidity over water $\mathrm{RH}_{\mathrm{w}}$ and the horizontal wind velocities. The internal calculation of horizontal winds is based on Global Positioning System (GPS) tracking. To calculate the relative humidity with respect to ice, RHi we used the formula: $R H_{i}=R H_{\mathrm{w}} \times \frac{e_{\mathrm{sw}}(T)}{e_{\mathrm{si}}(T)}$, where $\mathrm{RH}_{\mathrm{w}}$ is the relative humidity with respect to water and $e_{\mathrm{sw}}(T)$ denotes the saturation vapour pressure over water and $e_{\mathrm{si}}(T)$ the one over ice. The specific humidity q was estimated using $e_{\mathrm{sw}}(T)$ and additional the pressure profile, with: $q=0.622 R H_{\mathrm{w}} \frac{e_{\mathrm{sw}}(T)}{p}$, after WMO (2006) and Sonntag (1990). A review of the use of different formulae for the estimation of relative humidity over water and over ice was presented by Murphy and Koop (2005). They found that all commonly used expressions for vapour pressure are within $1 \%$ 
of each other for temperatures between 170 and $273 \mathrm{~K}$. In the following calculations of RHi we also applied the WMO formula because it is consistent with the one used for radiosonde measurements.

\subsection{Trajectory analysis}

We used the three-dimensional trajectory model LAGRANTO (LAGRangian ANalysis TOol, cf. Wernli and Davies, 1997) to examine the history of air parcels, which were detected from radiosondes over Northern Germany. LAGRANTO was driven by the wind fields of the operational ECMWF analyses and allows the calculation of kinematic Lagrangian trajectories. Backward trajectories of air masses were calculated and are characterized by thermo- and hydrodynamic quantities like temperature, relative humidity over ice, the specific humidity, cloud ice water content (CIWC), and the vertical velocity.

\subsection{ECMWF analyses}

In order to combine radiosonde and lidar measurements with meteorological fields on isentropic surfaces, we used the operational analyses of the ECMWF based on the integrated forecasting sys-

(a)

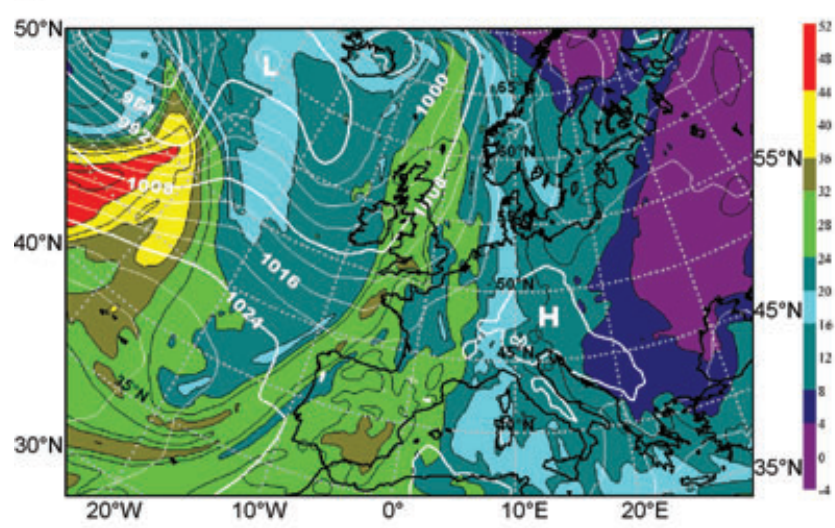

(c)

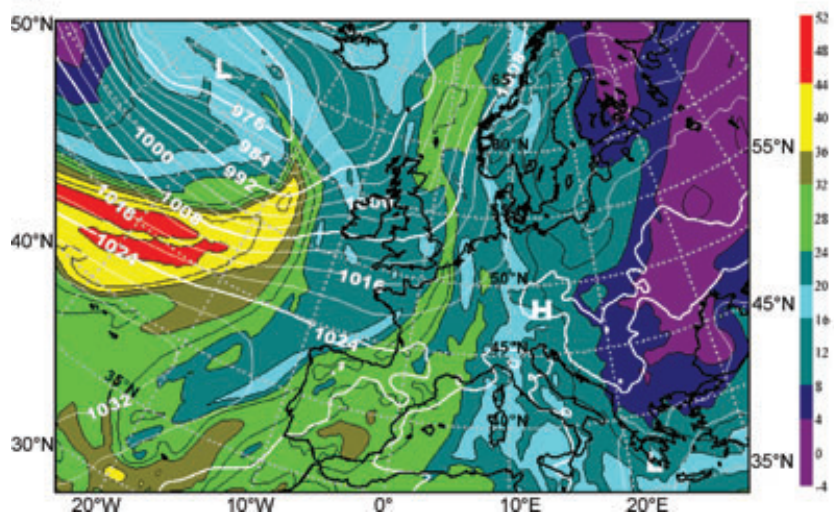

tem (IFS) (see also www.ecmwf.int) as an additional database. ECMWF applies a 4D-Var assimilation scheme and a dynamical model with a spherical spectral resolution of T799 (the midlatitudinal grid length is about $25 \mathrm{~km}$ ) and takes 90 layers up to the mesosphere into account. The calculation time interval is $12 \mathrm{~min}$, but $6 \mathrm{~h}$ interval for saving data. From these we calculated geopotential height, temperature and relative humidity over ice. The ERA - INTERIM analyses with the same physics but with lower resolution provide cloud ice water content as measure of homogeneous freezing, which was not permanently available for operational analyses.

\section{Case study}

\subsection{Synoptic overview}

On 13 February 2006, a surface low pressure system over the central Northern Atlantic was accompanied by a large high pressure bridge spanning from the Iberian Peninsula to Scandinavia on its southeastern flank (not shown). In the centre of the high pressure region over Austria a core pressure of $1030 \mathrm{hPa}$ was attained. On the next day as shown in Figs. 1a and c warm

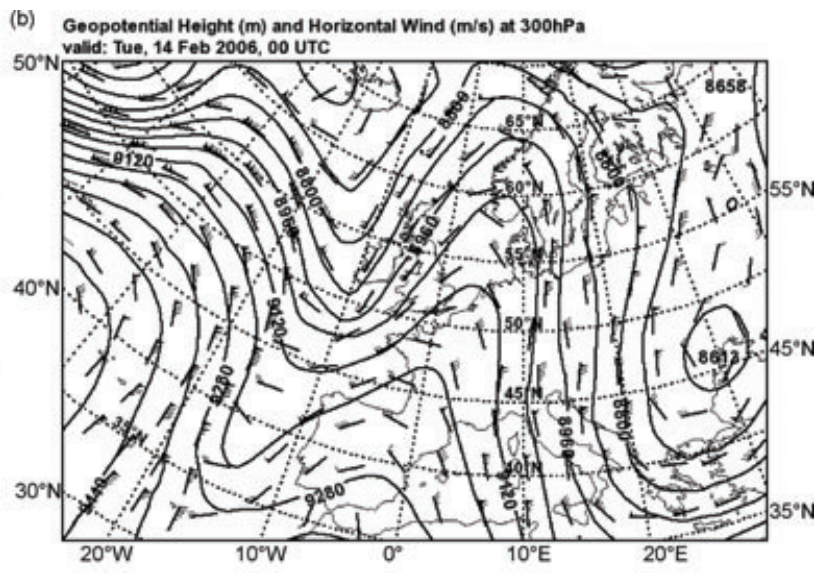

(d) Geopotential Height $(\mathrm{m})$ and Horizontal Wind $(\mathrm{m} / \mathrm{s})$ at $300 \mathrm{hPa}$

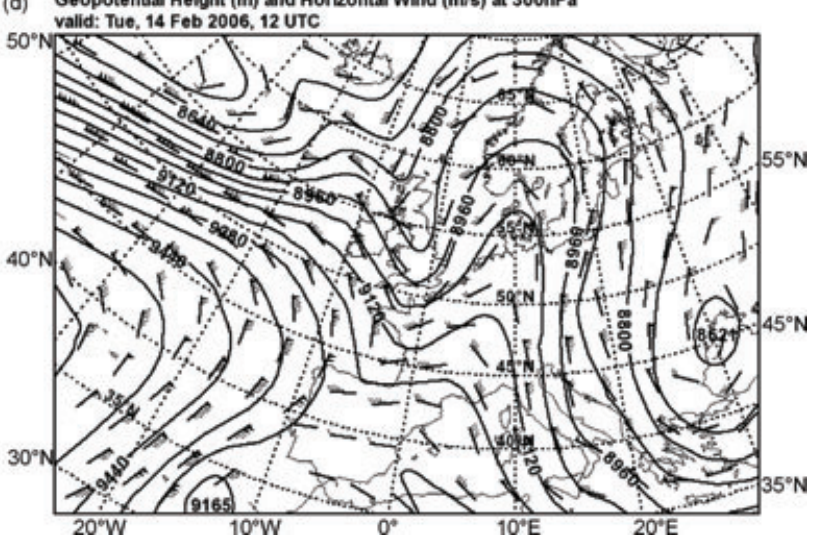

Fig. 1. Operational T799/L90 analyses of the ECMWF on 14 February 2006 valid at (a), (b) 0:00 UT and (c), (d) 12.00 UT, respectively. Panels (a) and (c) show the mean sea level pressure (hPa, white solid lines) and equivalent potential temperature $\left({ }^{\circ} \mathrm{C}\right.$, color bar) at the $850 \mathrm{hPa}$ level, and panels (b) and (d) depict the geopotential height (m, solid lines) and horizontal winds ( $\mathrm{m} / \mathrm{s}$, barbs) at the $300 \mathrm{hPa}$ pressure level. 
(a)
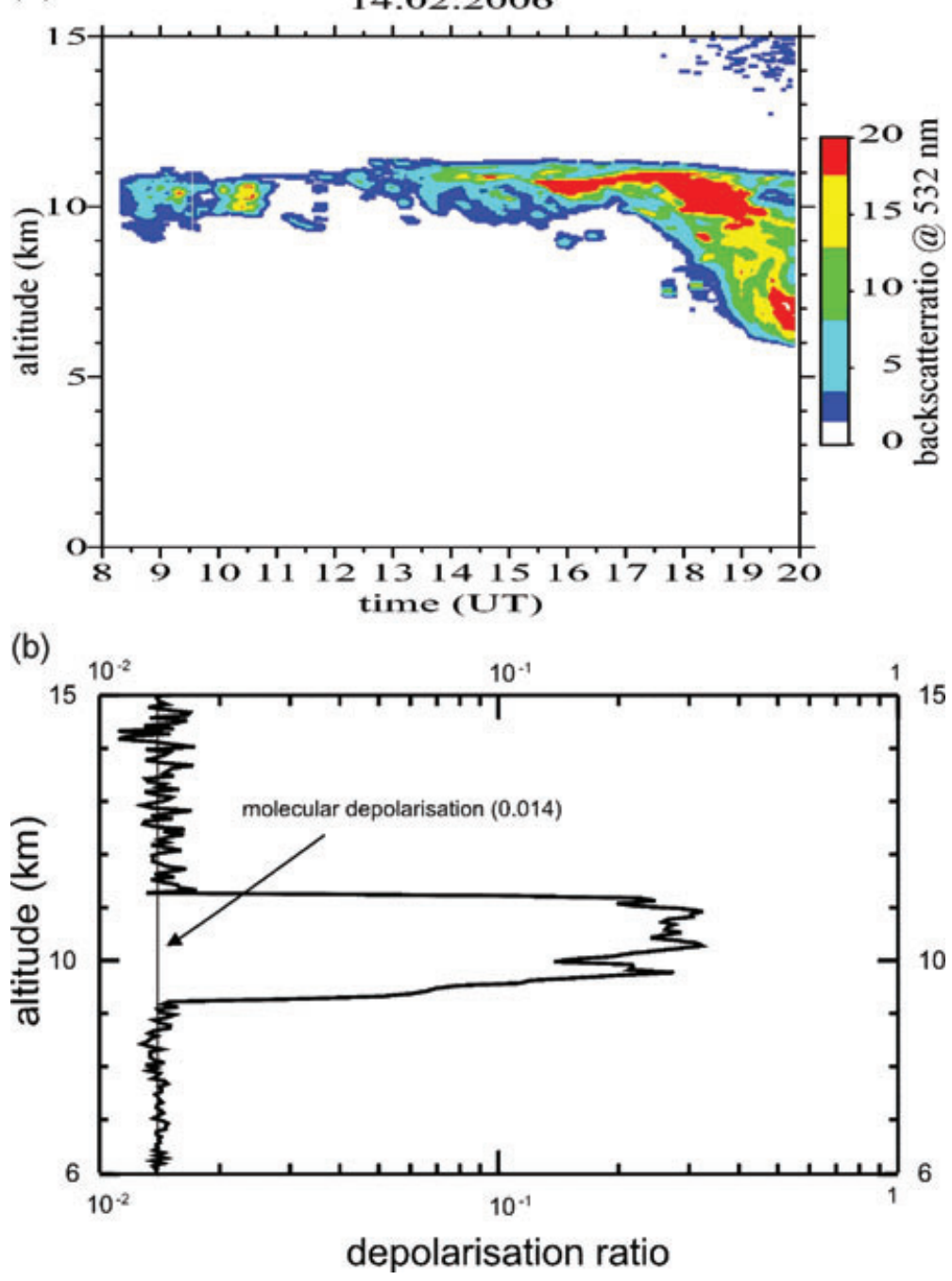

Fig. 2. Aerosol backscatter ratio $\mathrm{R}_{\lambda}$ (a) at $532 \mathrm{~nm}$ wavelength above Kühlungsborn between 8:00 and 20:00 UT, and depolarisation ratio (b) averaged between 16:45 and 17:42 UT on 14 February 2006.

fronts both over western France as well as on the eastern edge of the anticyclone over eastern Poland were analysed. In between, Northern Germany was influenced by high pressure. From 14 February, 0:00 UT, to 15 February, 0:00 UT, the high air pressure decreased and a cold front arrived over western Germany. Figure $1 \mathrm{~b}$ and d illustrates the evolution of the upper air flow at $300 \mathrm{hPa}$ in the first half of 14 February 2006, where the Rossby wave propagated eastward and steeped over Northern Europe. Over Central Europe, the air masses were sinking because of their clockwise rotation in the high-pressure area below about $500 \mathrm{hPa}$. The associated warming and drying of the descending air caused a clear sky up to about $5 \mathrm{~km}$. That means that during the lidar measurements on 14 February 2006 no low level clouds existed over Northern Germany.

\subsection{Lidar observation}

On the 14 February 2006 we examined the atmosphere with the lidar between 8:00 and 20:00 UT. During the whole observation period, a strong backscatter signal at $532 \mathrm{~nm}$ wavelength was detected near the tropopause region (Fig. 2a).

Between 8:00 and 12:00 UT we observed vertically thin ice clouds layers at about 9-11.4 km (Fig. 2a). Arguments for their identification as ice particles are given below. Over the whole time period the sharp decrease of the backscatter signal above the cirrus clouds showed a very distinct border between the upper troposphere and the dry and clean stratosphere. Furthermore we found an increase of the tropopause height (identified as the sharp upper edge of cirrus cloud) of about $300 \mathrm{~m}$ over the first half of the measurement period $(6 \mathrm{~h})$ and a decrease in the second half with a maximum height of about $11.4 \mathrm{~km}$ between 14:00 and 16:00 UT. We observed a "cirrus cloud hole" with two weakly backscattering layers between 11:00 and 12:00 UT (shown in blue in Fig. 2a). During this period the cirrus cloud was invisible for the human eye. In the evening (after 19:00 UT), high backscatter ratios were also detected at lower altitudes from 6 to $11 \mathrm{~km}$ (Fig. 2a). 
Over the whole time period (8:00 to 20:00 UT) the depolarisation ratio $\delta_{\mathrm{p}, 532}$ was determined. As an example in Fig. $2 \mathrm{~b}$, the depolarisation ratio averaged over a period of $57 \mathrm{~min}$ around 17:15 UT is shown. Between 9.3 and $11.3 \mathrm{~km}$ the depolarisation ratio was strongly increased with a maximum value of 0.35 at about $10.5 \mathrm{~km}$ altitude. That means, a layer of non-spherical particles (ice or solid aerosol particles) existed right below the tropopause. With temperatures of about $-61{ }^{\circ} \mathrm{C}$ detected from nearby radiosonde observations and a depolarisation ratio $\delta_{\mathrm{p}, 532}>0.3$ in this layer, we can assume the occurrence of ice particles. The 'cirrus cloud hole' depolarization ratio $\delta_{\mathrm{p}, 532} \approx$ $0.05 \ldots 0.2$ between 11:00 and 12:00 UT is in accordance with the smaller backscatter ratio. This indicates a reduced amount of ice crystals in this period. After this 'cirrus cloud hole', the aerosol backscatter ratio increased in magnitude up to about 10 inside the cirrus and the cloud layer thickened gradually. In the evening (from 19:00 UT), where the aerosol backscatter remained high between 6 to $11 \mathrm{~km}$ altitudes, we observed a lower depolarisation of 0.02 to 0.03 . We conclude that the lower clouds now contain much more aqueous solution droplets than ice crystals. This is in accordance with a high relative humidity measured from radiosondes launched at Kühlungsborn during this period.

\subsection{ECMWF analysis on isentropic surfaces}

In Fig. 3 the EPV distribution is shown at the $315 \mathrm{~K}$ isentropic layer for Northern Hemisphere, as a characteristic layer of the

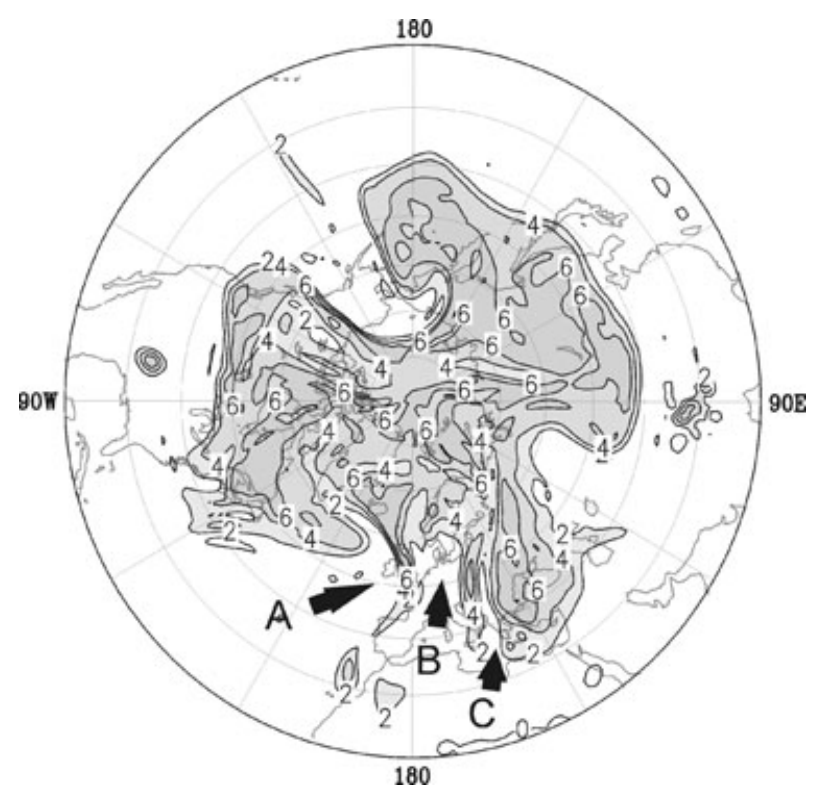

Fig. 3. EPV map of ECMWF analysis at the $315 \mathrm{~K}$ isentropic surface on 14 February 2006, 12 UT. Contour interval is $2 \mathrm{PVU}$ (1 PVU = $10^{-6} \mathrm{~K} \mathrm{~m}^{2} \mathrm{~kg}^{-1} \mathrm{~s}^{-1}$ ). Values larger than $2 \mathrm{PVU}$ are shaded. Arrows A, $\mathrm{B}$, and $\mathrm{C}$ mark special anticyclonic air masses which are described in Section 3.3. tropopause region on 14 February 2006, 12:00 UT. The greyshaded area represents stratospheric air masses where the 2 PVU (1 PVU $=10^{-6} \mathrm{~K} \mathrm{~m}^{2} \mathrm{~kg}^{-1} \mathrm{~s}^{-1}$ ) contour marks the dynamical tropopause. A hemispheric Rossby wave structure is found in extra-tropical latitudes with five poleward intrusions of subtropical air: over Alaska, Middle Russia, and three of them over the Northern Atlantic - European region. Using the types of RWB events defined by Peters and Waugh (1996), we identify a P1-RWB event over Alaska and a P2-RWB event over Middle Russia. The Northern Atlantic region was influenced by a poleward downstream RWB event (marked by arrow A) that developed during the 2 days before 14 February 2006. Central Europe was gradually influenced by anticyclonic air (marked by arrow B) due to a strong RWB event over the eastern Atlantic 4 days before 14 February 2006 (not shown). In combination with the upstream RWB event (A), anticyclonic air persisted over Central Europe for some days. There existed a third smaller anticyclonic air mass (marked by arrow C) over southeastern Europe belonging to an older RWB event which remained over Europe due to the blocking situation over Middle Russia. As a result of the RWB event, strong equatorward extrusions of stratospheric air (sometimes called streamer, e.g. Wernli and Davies, 1997) occurred on the eastern and western flank of the anticyclonic air mass (B) over Central Europe related to strong zonal shears. It must be noted, that the anticyclonic air mass marked with the arrow B was observed by our lidar measurements and radiosonde soundings during the campaign.

A detailed regional analysis of EPV, temperature, specific humidity, and relative humidity over ice is shown in Figs. 4 and 5. For 6-hourly data on 14 February 2007 over Central Europe the upper panel of Fig. 4 shows a slow eastward drift of all three anticyclonic air masses A, B, C. There existed a centre of very low EPV of about 0.15 PVU in the air mass B which changed its position and structure only marginally from 6:00 to 18:00 UT indicating a stagnation point over Mecklenburg. This finding agrees with analyzed horizontal winds at this level (not shown). Note there was another nearly stationary centre of low EPV over Eastern Spain.

The specific humidity pattern (lower panel, Fig. 4), which is approximately a passive tracer, shows a good spatial correspondence with the EPV fields and their 12-hourly evolution. Generally, low EPV values correspond to high specific humidity at the $315 \mathrm{~K}$ isentropic surface. In the transition zone between tropospheric and stratospheric air over Northern Germany we found specific humidity values of about $2-310^{-5} \mathrm{~kg} \mathrm{~kg}^{-1}$ increasing in magnitude southeastwards and decreasing northeastwards. As shown in the middle panels of Fig. 4, the coldest temperature area at $315 \mathrm{~K}$ was placed over southern Scandinavia with a centre over Sweden due to the adiabatically rising air induced by the poleward RWB event B.

An extension of the relatively cold area reached Northern Germany with temperatures of about $212 \mathrm{~K}\left(\sim-61{ }^{\circ} \mathrm{C}\right)$ between 6:00 and 12:00 UT. In the overlapping zone between an area of 


\section{ECMWF-analysis, isentropic layer $315 \mathrm{~K}, 14.02 .2006$}
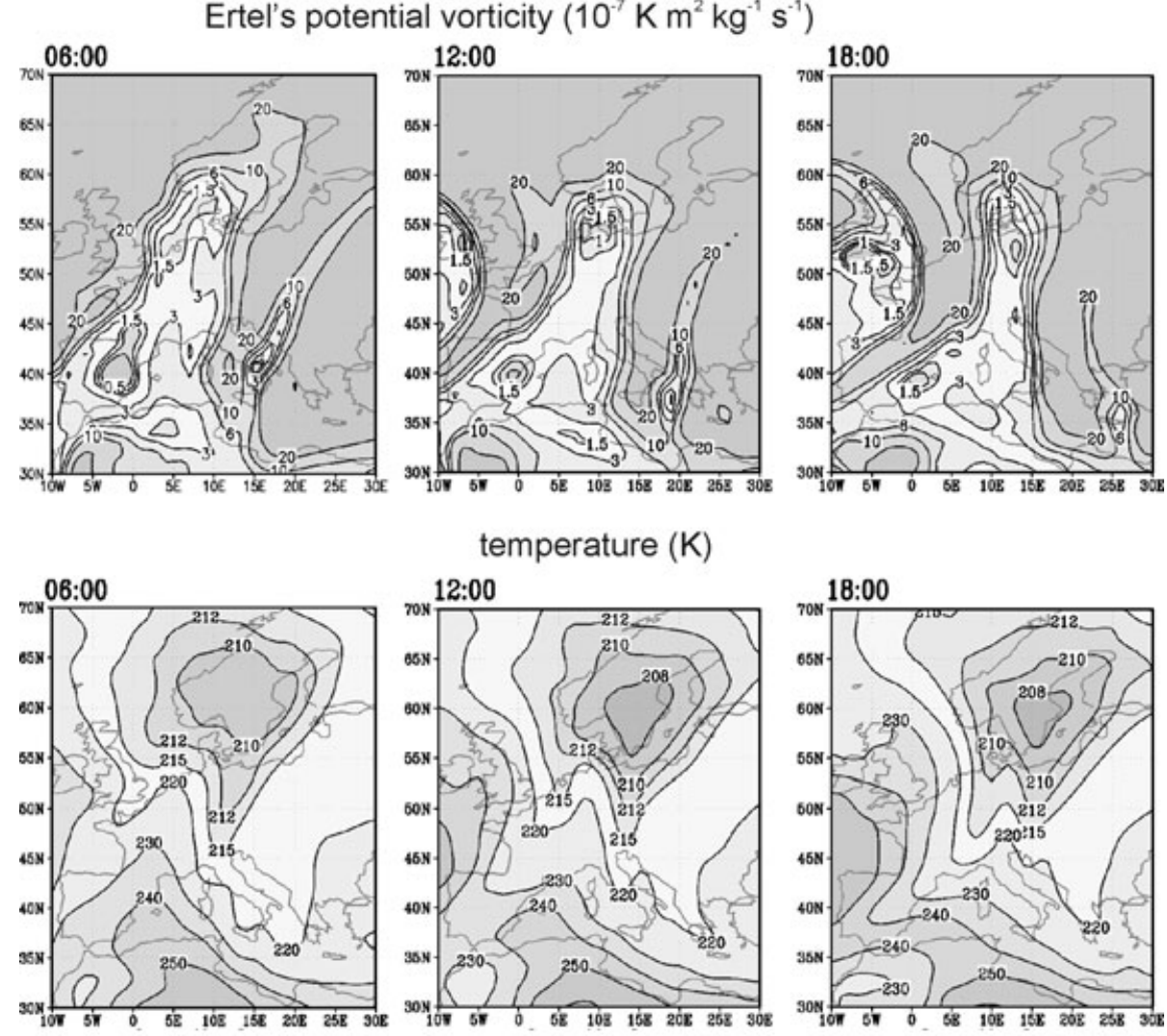

specific humidity $\left(10^{-5} \mathrm{~kg} \mathrm{~kg}^{-1}\right)$
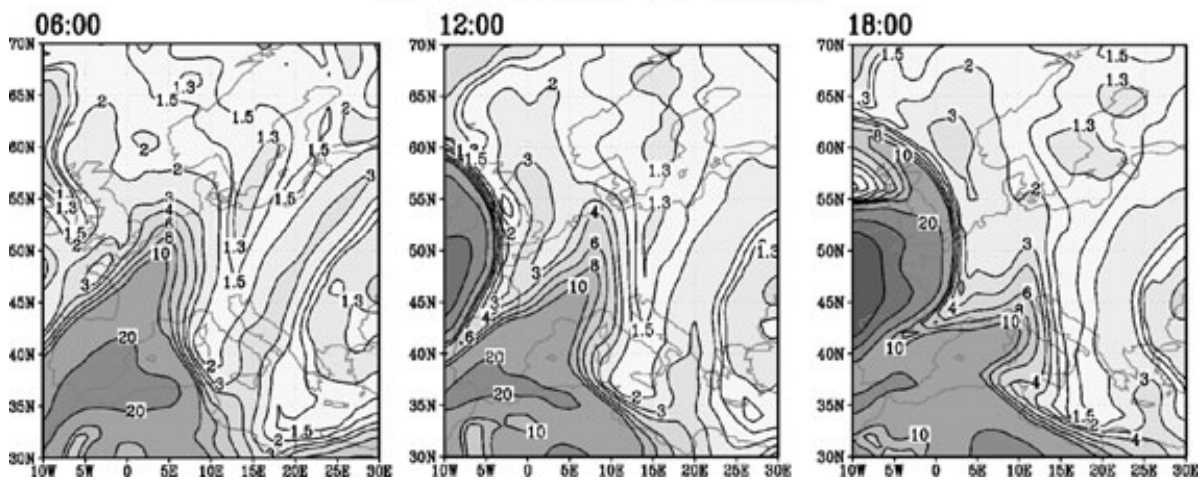

Fig. 4. Regional maps of EPV, temperature and specific humidity at the $315 \mathrm{~K}$ isentropic surface on 14 February 2006 for 6:00, 12:00 and 18:00 UT.

relative low temperatures and an area of relative high specific humidity good conditions for the formation and existence of ice clouds occurred as described in the Introduction. Figure 5a depicts the horizontal distribution of relative humidity over ice at the $315 \mathrm{~K}$ isentropic layer on 14 February 2006, 12:00 UT. Over Europe along a line from Spain to Scandinavia, a coherent elongated region with $\mathrm{RHi}>80 \%$ was analysed where cirrus clouds can be expected to occur from theory and former observations. The RHi maximum is placed over Denmark with a value of $108 \%$ indicating supersaturation. There exists a strong coin- cidence of high RHi values with the anticyclonic EPV anomaly (B) as well as for air masses (A) and (C). At 18:00 UT the air mass with RHi $>105 \%$ passed Northern Germany (not shown).

In Fig. $5 \mathrm{~b}$ the height dependence of isentropic layers is shown for a regional height cross section at $54^{\circ} \mathrm{N}$. The height of $315 \mathrm{~K}$ isentropic layer increased from $\sim 8.5 \mathrm{~km}$ altitude at the Greenwich meridian to about $\sim 10.5 \mathrm{~km}$ at $13^{\circ} \mathrm{E}$ with a local minimum at about $8^{\circ} \mathrm{E}$. For the 330 and $350 \mathrm{~K}$ isentropic layers also an increase of altitude occurred over Central Europe from west to east, but eastwards of $10^{\circ}-15^{\circ} \mathrm{E}$ their heights were decreasing. 
(a)

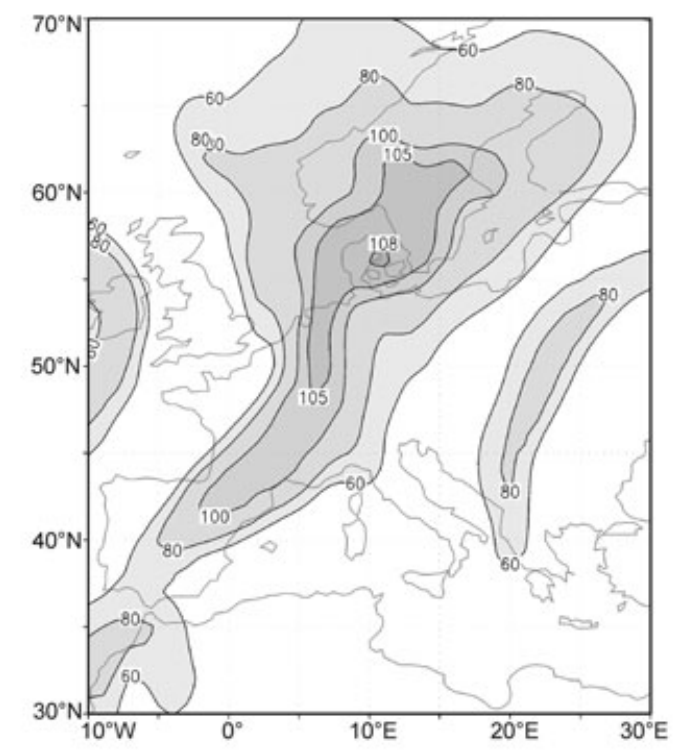

(b)

Fig. 5. Maps of ECMWF analysis for RHi $>60 \%$ are shown based on 14 February 2006, 12:00 UT, (a) latitude - longitude crosssection at the $315 \mathrm{~K}$ isentropic layer, (b) height-longitude crosssection of potential temperature $\left(\mathrm{K}\right.$, thin lines) at $54^{\circ} \mathrm{N}$ latitude. The bar marks the position where lidar observations detected cirrus clouds from 8:00 to 20:00 UT.

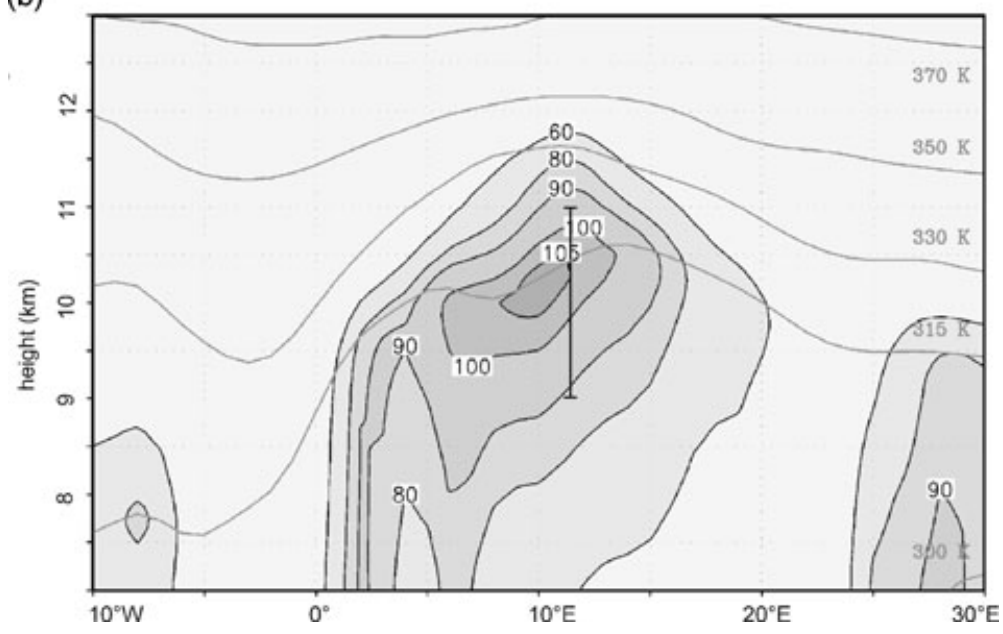

This behaviour is related to the poleward and upward intrusion of the anticyclonic air mass (B) over Central Europe.

Thus, according to the RHi maps, there is a direct interconnection between the increase of isentropic in the upper troposphere and the increase of relative humidity over ice at these levels over Europe as also shown in Fig. 5b. Over Central Europe there existed an altitude region with $\mathrm{RHi}>80 \%$. This region shows an upward tilt with height from west to east and it was moving weakly eastward as revealed by additional analysed plots for 6:00 and 18:00 UT. Thus, based on the RHi maps of ECMWF analyses, cirrus clouds over Kühlungsborn could be expected to occur between 9 and $11.4 \mathrm{~km}$ altitude over the whole time period from 06:00 UT till 18:00 UT. Just in that height region during that time, the Kühlungsborn lidar actually detected cirrus clouds. Note, the temporal evolution of the cirrus cloud as shown in Fig. 2 is in agreement with the temporal development of maps of $\mathrm{RHi}>80 \%$.

\subsection{Radiosounding}

On 14 February 2006, all five radiosonde stations in Northern Germany were located below the anticyclone, hence, the observed in situ profiles can directly be used for the medium-scale evaluation of the vertical and horizontal thermodynamically behaviour of the upper troposphere during the cirrus cloud observations.

The analysis of the radiosoundings revealed an eastward increase of the $315 \mathrm{~K}$ isentropic surface from $9.5 \mathrm{~km}$ at Emden to $10.4 \mathrm{~km}$ altitude at Lindenberg. Due to this lifting, the temperature at $315 \mathrm{~K}$ decreased from $-54.0^{\circ} \mathrm{C}$ at Emden to $-63.3^{\circ} \mathrm{C}$ at 
Lindenberg. The zonal wind decelerated, and the negative value of the meridional wind increased significantly from west to east. That means that the air mass experienced a stronger anticyclonic rotation in eastward direction. The balloon drift (distance from starting point) is smallest at Kühlungsborn due to the weaker winds there. The relative humidity over ice (water) diminished from 88 (52)\% over Emden to only 45 (26)\% over Lindenberg. The specific humidity declined along the lifting of the $315 \mathrm{~K}$ isentropic level. The analysis of the tropopause height measured by all five stations reveals a maximum tropopause altitude with $11.4 \mathrm{~km}$ over Kühlungsborn at noon with a decrease of about $350 \mathrm{~m}$ towards the surrounding stations. The tropopause temperature decreased significantly from west to east by $2.5 \mathrm{~K}$ and amounted to about $212 \mathrm{~K}$ in the mean. The relative humidity over ice (water) shows its largest values over Kühlungsborn with a decrease towards the surrounding stations. The values of specific humidity were almost constant at about $0.8 \times 10^{-5} \mathrm{~kg} \mathrm{~kg}^{-1}$ for all 5 stations in the tropopause region. This mean value is about two times smaller than the one determined from ECMWF analyses. Note that the RS92 radiosonde has a dry bias (Vömel et al., 2007), thus the real relative humidities over ice can be much higher.

Now we discuss shortly the vertical profiles of the radiosonde launches at Kühlungsborn explicitly because the maximum drift of the balloon to the starting point was not larger than about $6 \mathrm{~km}$ in the whole troposphere. In Fig. 6a, the observed temperature, relative humidity over water and ice; and in b) the wind components are shown for the radiosounding at 14:26 UT. The temperature profile decreases continuously up to a height of about $11.45 \mathrm{~km}$ where the tropopause is placed. In the height region between about $10 \mathrm{~km}$ and about $11.45 \mathrm{~km}$ the largest relative humidity over ice with RHi > 80\% (with RHw > 40\%) was observed. As shown before in this altitudinal region the backscattered lidar signal was strongly enhanced. In Fig. 6b, in a height of about $4 \mathrm{~km}$ the meridional wind changes its direction from north to south and increases higher up to about $10 \mathrm{~m} \mathrm{~s}^{-1}$. The zonal wind is mainly directed eastwards with weaker values below $4 \mathrm{~km}$, and a relative maximum in the tropopause region.

The tropopause height over Kühlungsborn as estimated from two radiosoundings at 12:28 UT, and 14:26 UT, was 11.35 and $11.45 \mathrm{~km}$, respectively. Thus, the ascent rate of the tropopause height is in the order of $100 \mathrm{~m}$ per $2 \mathrm{~h}\left(\sim 1.4 \mathrm{~cm} \mathrm{~s}^{-1}\right.$, respectively $-0.13 \mathrm{~Pa} \mathrm{~s}^{-1}$ ), this change is also captured by the lidar measurements at noon (see Fig. 2).

\subsection{Trajectories analysis}

To study the formation of the observed cirrus clouds and to determine the origin of the air masses, an ensemble of backward trajectories was calculated. Altogether, 15 trajectories were launched in a box between $10^{\circ} \mathrm{E}$ and $12^{\circ} \mathrm{E}$ and $54^{\circ} \mathrm{N}$ and $55^{\circ} \mathrm{N}$ surrounding Kühlungsborn at six pressure level from 300 to $200 \mathrm{hPa}$ at $12 \mathrm{UT}$ on 14 February 2006. The LAGRANTO back- (a)

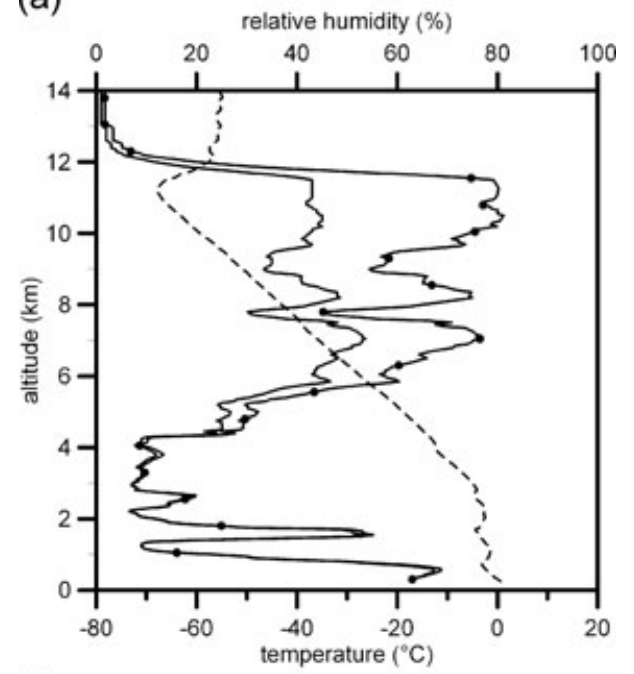

(b)

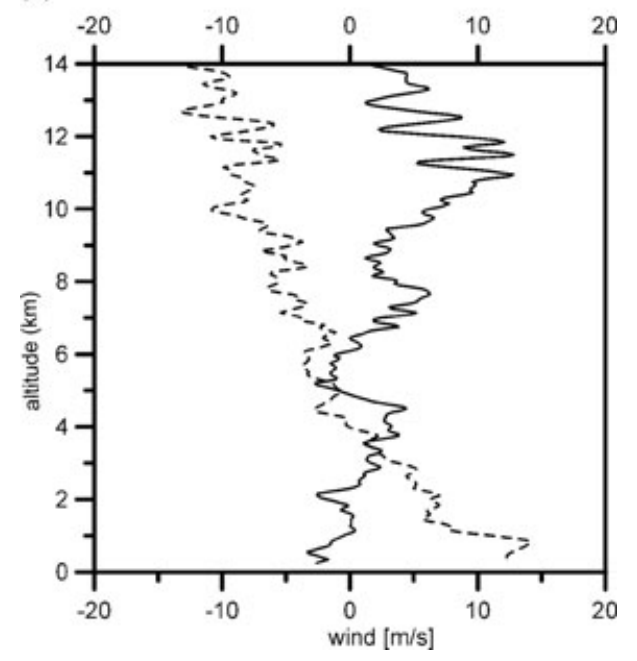

Fig. 6. Vertical profiles of (a) temperature $\left({ }^{\circ} \mathrm{C}\right.$; dashed line), $\mathrm{RHw}(\%$, thin line) and RHi (\%; line with dots). (b) Zonal (full) and meridional (dashed) winds $(\mathrm{m} / \mathrm{s})$ observed by a radiosonde launched at Kühlungsborn on 14 February 2006, 14:26 UT.

ward trajectories are driven by operational 6 hourly ECMWF analyses, and Fig. 7 shows the path of the centre-of-gravity trajectories for 300,260 and $240 \mathrm{hPa}$, respectively. There is a pronounced anticyclonic motion of the air parcels from the west coast of the British Isles towards the east. Generally, air parcels descended on their backward paths, which are in agreement with their true lifting on the way towards the measurements site. This flow pattern agrees with the anticyclonic EPV-anomaly at the $315 \mathrm{~K}$ isentropic layer as shown in Fig. 4.

The ascent of the air parcels was associated with an overall increase of the relative humidity over ice, see lower panel in Fig. 7. About $10 \mathrm{~h}$ before 12:00 UT, 14 February 2006, the air parcels attained RHi $>100 \%$, i.e. ice supersaturation. However, to form ice particles by homogeneous freezing of aqueous droplets, 

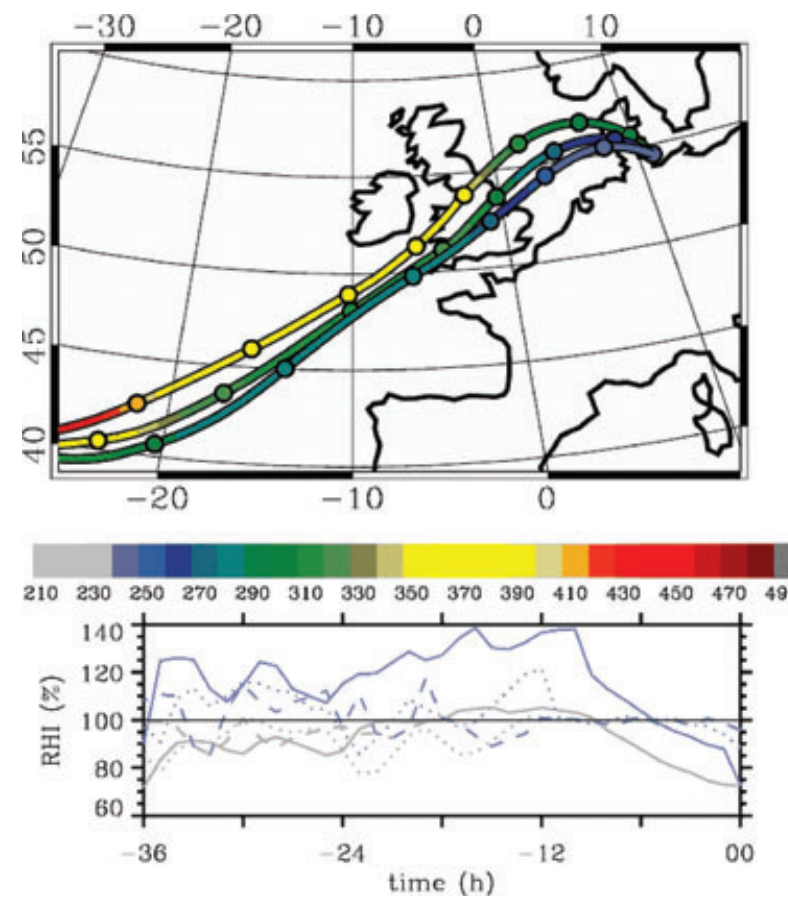

Fig. 7. Upper panel: Positions and pressure (hPa, color coded) of the center of gravity of trajectories launched inside the box $\left(54^{\circ} \mathrm{N}, 55^{\circ} \mathrm{N}\right)$ and $\left(10^{\circ} \mathrm{E}, 12^{\circ} \mathrm{E}\right)$ at 300,260 , and $240 \mathrm{hPa}$, respectively. Circles denote 12 hour increments. Lower panel: RHi along the mean trajectories released at 300 (solid lines), 260 (dotted), and $240 \mathrm{hPa}$ (dashed), respectively. The grey lines denote RHi averaged over all trajectories, whereas the blue lines denote RHi calculated with the specific humidity averaged over all trajectories added by its rms deviation.

a supersaturation of $140 \%$ is necessary, e.g. Kaercher and Lohmann (2002), Kaercher et al. (2006). Although ice supersaturation was recently included in the ECMWF IFS (see Tompkins et al., 2007), maximum values of RHi of up to $110 \%$ were found

(a)

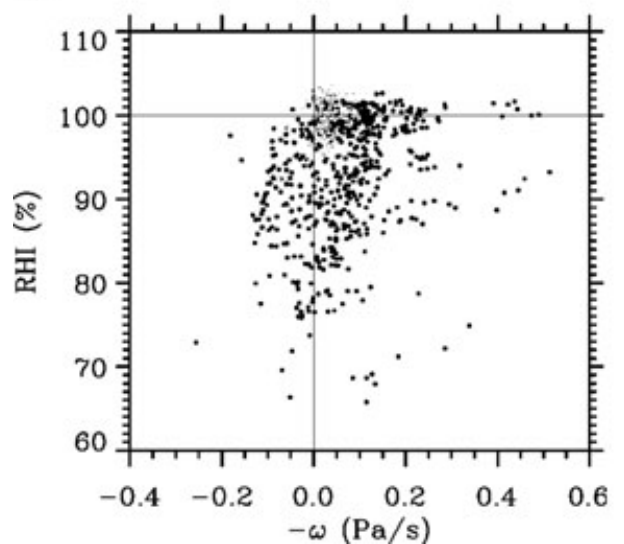

along the trajectories which corresponds to Fig. 5. However, if the spread of the (rather uncertain) upper tropospheric humidity values along the trajectory ensemble is taken into account, higher values of RHi along the trajectories are possible (blue lines in the lower panel of Fig. 7). It must be noted, that this result is not an accurate proof of the actual formation process of the ice crystals but indicates that small variations of the background humidity alone allow for homogeneous ice nucleation. Thus, the cirrus clouds observed by the lidar on 14 February 2006 were most probably formed over the North Sea $10-18 \mathrm{~h}$ before detection. The air mass was ascending along a warm conveyer belt, which originated from the subtropical Atlantic boundary layer.

In order to continue the study of the link between ascending air masses and the occurrence of cirrus clouds we present in Fig. 8 scatter plots of the correlation between RHi and vertical velocity as well as between CIWC and vertical velocity along their backward trajectories started at $240 \mathrm{hPa}$ over Mecklenburg. Here as done in many other studies the RHi and CIWC parameter are used as a proxy for cirrus clouds appearance. Only values are shown for $T<233 \mathrm{~K}$ (black dots) and $T<213 \mathrm{~K}$ (grey dots). The positive relation between increasing vertical velocity and RHi and CIWC (for $T<235 \mathrm{~K}$ ) is an important result and agrees well with results from Immler et al. (2008) and Mace et al. (2006). Furthermore, the appearance of cirrus clouds during the descent was also observed by Mace et al. (2006) in their climatological study. As in our study, they found that thin (cold) clouds correlate stronger with weaker but ascending air masses.

\section{Other RWB events with cirrus cloud evidence from 1997 to 2006}

During ten winters, from 1997 to 2006, lidar measurements were performed at Kühlungsborn during clear weather conditions. Among many other cases, we selected three further cases (Fig. 9)

(b)

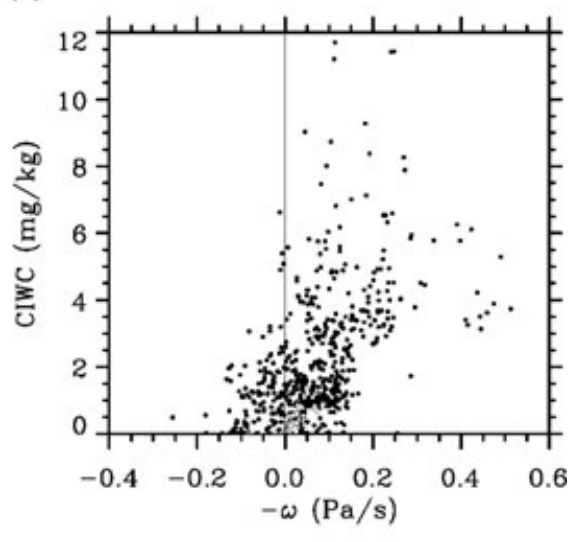

Fig. 8. Scatter plot between (a) vertical velocity $(\mathrm{Pa} / \mathrm{s})$ and RHi (\%); and (b) vertical velocity $(\mathrm{Pa} / \mathrm{s})$ and updraft and CIWC (mg/kg) along the backward trajectories released in a box centred over Kühlungsborn at $240 \mathrm{hPa}$ on 14 February 2006, 12:00UT. The trajectory is every hour (more details see text in Section 3.5). 

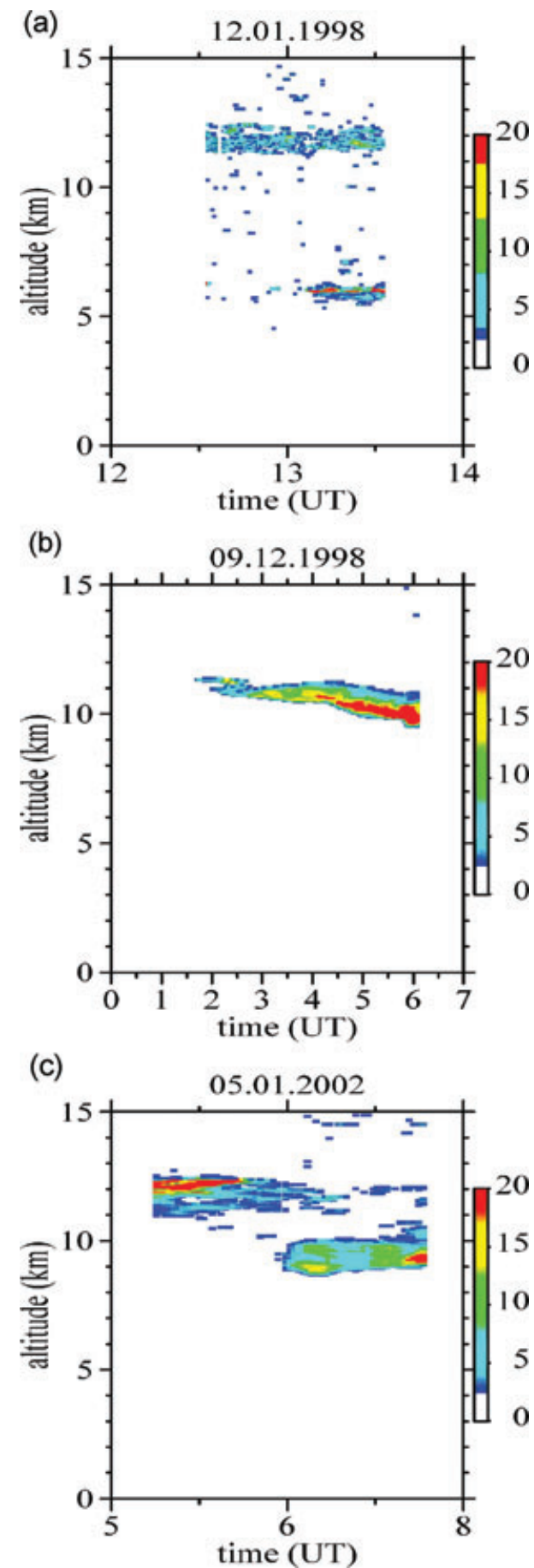

Fig. 9. Aerosol backscatter ratio $\mathrm{R}_{\lambda}$ at $532 \mathrm{~nm}$ wavelength above Kühlungsborn; (a) on 12 January 1998, (b) on 9 December 1998 and (c) on 5 January 2002.

showing a similar dynamical behaviour with high and thin cirrus clouds as presented for the case of 14 February 2006 (case 1).

On 12 January 1998 (case 2) the backscatter signal based on lidar measurements shows high intensity at about $12 \mathrm{~km}$ height between 12:31 and 13:33 UT, on 9 December 1998 (case 3) at about $11 \mathrm{~km}$ height with decreasing altitude down to $10 \mathrm{~km}$ between 1:20 and 6:13 UT, and on 5 January 2002 (case 4) at about $12 \mathrm{~km}$ between 5:18 and 7:44 UT but additionally a second layer occurred below at about $9 \mathrm{~km}$ between 6:30 and 7:44 UT.

For those days the investigation of EPV, specific humidity and temperature on the $315 \mathrm{~K}$ isentropic layer of ECMWF analyses shows poleward RWB events (not shown). In summary, we found that during the evolution of a poleward RWB event, relative wet air masses with low EPV values (anticyclonic rotation) penetrate from southwest to northeast at the western flank of a high pressure system and ascending in the upper troposphere that means the trajectories are anticyclonically curved over Northern Germany. Due to the adiabatic ascending air masses in the northeastern area an upper cold air mass region occurred with temperatures lower than about $-60{ }^{\circ} \mathrm{C}$. In Fig. 10 the RHi distributions the longitude-height cross sections at $54^{\circ} \mathrm{N}$, and the latitude-longitude cross section at 330 and $315 \mathrm{~K}$ isentropic layer for ECMWF analysis over the North Atlantic-European region on 12 January 1998 (12:00 UT), on 9 December 1998 (6:00 UT), and on 5 January 2002 (6:00 UT) are shown, respectively.

As discussed before in an overlapping region between relative wet (southwestern) and cold (northeastern) air masses the conditions are fulfilled to expect cirrus clouds to occur (RHi > $80 \%$, lower panel of Fig. 10) where cirrus clouds have been really detected by lidar measurements during that time (see Fig. 9 , and upper panel of Fig. 10). That means that in the tropopause region relative high and thin layered cirrus clouds were observed during three further RWB events.

In order to review the four cases under synoptic aspects ERA - INTERIM maps at $300 \mathrm{hPa}$ were inspected. At different locations where CIWC had a regional maximum over middle Northern Europe, the approximated values of EPV have been picked up by visual inspection of the maps. Data from the Baltic Sea region (labeled $\mathrm{B}, 0-20^{\circ} \mathrm{E}, 50-65^{\circ} \mathrm{N}$ ) and the polar region (labeled $\mathrm{P}, 0-50^{\circ} \mathrm{W}, 65-80^{\circ} \mathrm{N}$ ) were selected. They are shown together with the vertical velocity in a scatter plot (Fig. 11a) where the points with the letter B mark values from the Baltic region and letter $\mathrm{P}$ the ones from polar regions for our four different cases. In all cases, the EPV values appeared to be well below the climatological value of 2 PVU indicating the subtropical origin of air masses. The mean vertical velocities (about $-0.15 \mathrm{~Pa} \mathrm{~s}^{-1}$ corresponds to about $3 \mathrm{~cm} \mathrm{~s}^{-1}$ at about $300 \mathrm{hPa}$ ) are indicating synoptic scale processes. The largest values of updraft were found in situations with small EPV. The most extreme case in this sense is the polar case 4P, but also under the Baltic cases the largest updraft took place for low EPV (3B). The case characteristics with respect to the CIWC are shown in Fig. 11b. The most extreme case is, again, $4 \mathrm{P}$, which connects fast updraft with large CIWC. The comparison of the different Baltic cases does not reveal such a clear picture. While the largest updraft appeared with medium CIWC (3B), most CIWC was found for medium updraft (2B). The samples from polar region showed 


\subsubsection{8 (12 UT) 09.12.1998 (06 UT) 05.01.2002 (06 UT)}
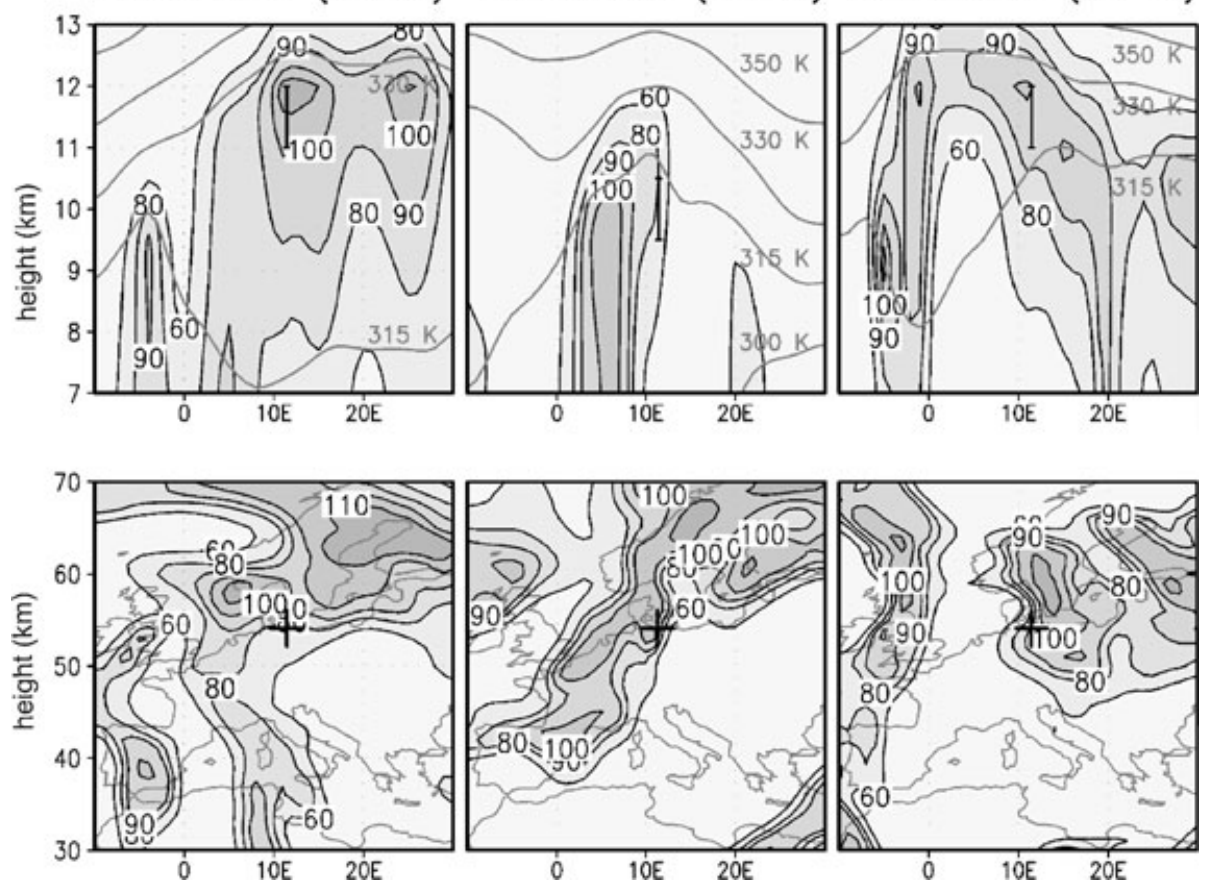

Fig. 10. Maps of ECMWF analysis for RHi > 60\% on 12 January 1998, 12:00 UT, on 9 December 1998, 6:00 UT and on 5 January 2002 , 6:00 UT are shown. Upper panel: Height-longitude crosssection at $54^{\circ} \mathrm{N}$ with different isentropic layers (lines). The bar marks the altitudinal region where the lidar at Kühlungsborn detected cirrus clouds. Lower panel: Latitude-longitude crosssection at $330 \mathrm{~K}$ (left) and $315 \mathrm{~K}$ (middle, right) isentropic layer, respectively. A cross marks the location of Kühlungsborn.

(a)

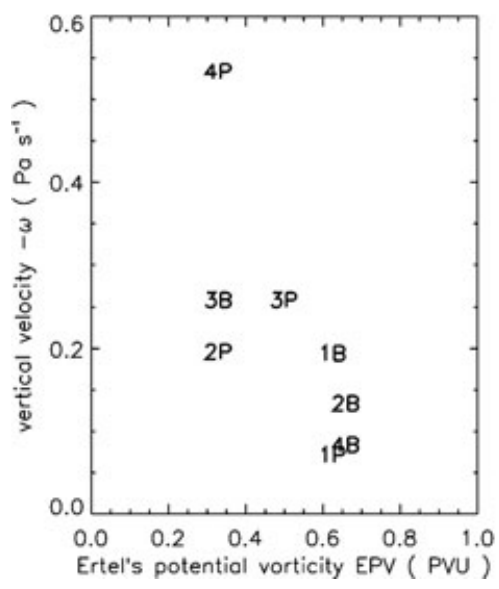

(b)

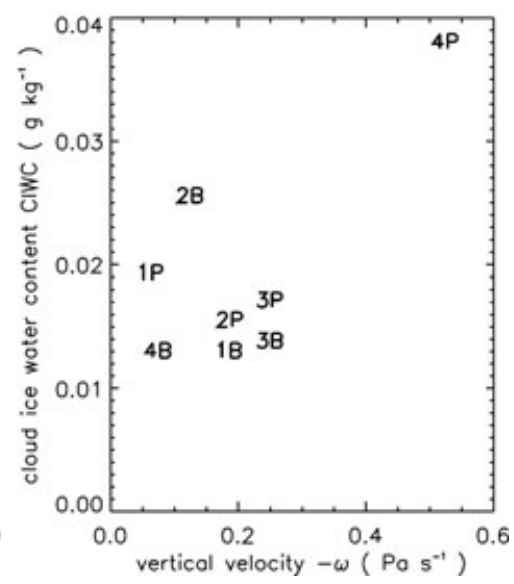

Fig. 11. Scatter plots showing (a) EPV and vertical velocity, and (b) vertical velocity and CIWC for selected regions and times (details see text in Section 4). Each point is labeled with a number for the case and a letter for the region of ice cloud appearance (B: Baltic sea region; P: polar region). an enhanced backscatter signal in the tropopause region, which indicates a high and thin layer of cirrus clouds. The lidar measurement, which we had exploited here uses a high vertical and temporal resolution in comparison to standard infrared satellite images. To study the spatial distribution of the cirrus clouds over Northern Europe during those days we used satellites images from satellites of MODIS, NOAA 14 and 17 (provided by http.//www.sat.dundee.ac.uk) in thermal channels between 7.17 and $11.3 \mu \mathrm{m}$. The satellite images (not shown) show weak 
cloud patterns, which are in agreement with our findings of cirrus clouds on 14 February 2006 (Fig. 1), on 12 January 1998, on 9 December 1998, and on 5 January 2002 (Fig. 9) over Kühlungsborn.

In general the overall structure and movement of satellitederived cirrus patterns followed the ECMWF EPV contour evolution on 330 or on $315 \mathrm{~K}$ isentropic layer as expected. In each case the satellite detected a nearly homogeneous structure of cirrus without any strong mesoscale structure, in difference to Spichtinger et al. (2005b). They found during specific RWB events patch-like structure in the satellite images over Central Europe, and linked them to different generation processes of inertia-gravity waves. If we compare our winter cases with the $10 \mathrm{yr}$ classification of lidar measurements at Salt Lake City, Utah (USA) (Sassen and Campbell, 2001) we could put our four cases into the group of high and thin cirrus clouds related to a ridge with a strong amplitude. From the study of Peters and Waugh (1996) we know that ridges like this are connected with poleward RWB events occurring frequently over the eastern Pacific Ocean-North America region.

That means more generally that during a poleward RWB event subtropical air mass is moving northeastward at the western flank of an anticyclone in connection with an uplift of the isentropic layers producing a region of relative cold air in the tropopause region. The related updraft velocity was estimated independently from observations and analyses and turned out to be characteristic for large-scale synoptic motion. On these scales, the ECMWF analyses allowed for a characterization of the background fields for cirrus existence. In the transition region between the relative wet air and relative cold air the condition for forming and existence of cirrus clouds is fulfilled. Statements on their detailed formation and characteristics require additional observations and are beyond the scope of this study. In a sensitivity study (Fig. 7) we showed, that homogeneous formation is possible and likely in the observed case. An intercomparison of eight cases of cirrus occurrence (Fig. 11) showed a correspondence between low EPV, updraft and CIWC. The low EPV is indicative for the subtropical origin of air masses and the updraft velocities are characteristic for synoptic-scale processes. While the Polar regions are typically cold and dry, they react sensitively to any imported moisture thus encompassing the formation of cirrus clouds. For the Baltic regions, however, the link between EPV, humidity and ice is not such unique, but it fits into the general picture. Based on this observational fact and with a well defined RWB index is should be possible to derive an empirical relationship between both the occurrence of high and thin cirrus clouds and poleward RBW events.

If the regions of poleward RWB are changing due to climatic changes of the circulation their influence on regional cirrus cloud formation and thus on the radiative impacts on climate could be very important. Our knowledge on the climatic impact of cirrus clouds is based on microphysical models and radiative transfer calculations. Cloud height and thickness have obviously a significant influence on the radiative effects including their microphysical structure. Nevertheless the role of RWB events in the formation process should not be discarded. Climate models based on monthly mean value must consider RWB events with a life-time of $2-5 \mathrm{~d}$ in a statistical sense. That's why it is important to quantify their occurrence and impact. The present indicator for RWB was EPV, but more advanced formulations in terms of EPV fluxes are available (Gabriel and Peters, 2008). At the other hand, a space and time covering operational cirrus cloud monitoring has to be established. The synthesis of data from both sources could give the present hypothesis of linked RWB and cirrus clouds a broader statistical basis.

\section{Summary}

RWB events have been identified very often in the upper troposphere over Mecklenburg, Northern Germany. During an anticyclonic poleward downstream RWB event a campaign deployed remote-sensing and in situ instruments was conducted on 13-15 February 2006. A backscatter lidar signal was used to identify cirrus clouds. Radiosoundings at Kühlungsborn were supplemented by German weather service operational soundings in Northern Germany. The results of these measurements were compared with ECMWF data analyses, and completed with comprehensive trajectory analyses to deduce the origin of the sampled air masses.

In maps of ECMWF analyses a strong adiabatic northeastward and upward transport of water vapour within the warm conveyor belt on the western side of the ridge over Northern Germany has been observed. The backscatter lidar at Kühlungsborn clearly identified high and thin cirrus clouds at an altitudinal region between 9 and $11.4 \mathrm{~km}$. In the tropopause region radiosoundings showed layers of subsaturated vapour pressure over ice but with a RHi $>80 \%$ just in time and altitude where the lidar detected cirrus clouds. From radiosoundings a relatively strong increase of the tropopause height of $100 \mathrm{~m}$ per $2 \mathrm{~h}$ on 14 February before 16:00 UT was determined in agreement with the lidar results.

The link between ascending air masses and the occurrence of cirrus clouds was investigated with RHi, vertical velocity and CIWC. Here as done in many other studies the RHi and CIWC parameter are used as a proxy for cirrus clouds appearance. The positive correspondence for temperatures $<235 \mathrm{~K}$ between increasing vertical velocity and RHi and CIWC is an important result and agrees well with results from Immler et al. (2008) and Mace et al. (2006).

In this study further three similar events have been analysed. Based on ECMWF INTERIM data we showed the strong link between the large-scale structure of low values of EPV, updraft and CIWC. The polar regions, in particular, reacted most sensitive on the import of moist air of subtropical origin. These results support our hypothesis that with a known climatology of poleward RWB events a parametrization of the formation or occurrence of high and thin cirrus clouds seems to be possible. 
The central idea of this paper was the use of EPV as an index for quantifying the intensity of RWB. In future idealized model studies of the temporal formation of cirrus clouds during such RWB events should be used to examine our knowledge about this complex process of cirrus cloud forming in order to develop a parametrization for radiative active upper tropospheric cirrus clouds based on advanced poleward RWB indices as for instance defined in Gabriel and Peters (2008).

\section{Acknowledgments}

The authors thank the German Science Foundation for funding this project under PE474/4 and PE474/7. Further we thank DWD and ECMWF for providing analyses data sets. We thank the LEWIZ team (http://www.iap-kborn.de/People.427.0.html) for launching radiosondes at Kühlungsborn and DWD for providing radiosonde data. We gratefully acknowledge the help of H. Voss and B. Wecke in producing Figs. 3-6, and 10 related to the isentropic analysis. The authors benefited from intense discussions with Prof. T. Peter (Zürich). Further the helpful comments of two unknown reviewers are appreciated.

\section{References}

Alpers, M., Eixmann, R., Höffner, J., Köpnick, T., Schneider, J. and coauthors. 1999. The Rayleigh/Mie/Raman lidar at IAP Kühlungsborn. J. Aerosol Sci. 30(Suppl. 1), 637-638.

Chen, T., Rossow, W. B. and Zhang, Y. 2000. Radiative effects of cloud type variations. J. Clim. 13, 264-286.

DeMott, P. J., Cziczo, D. J., Prenni, A. J., Murphy, D. M., Kreidenweis, S. M. and co-authors. 2003. Measurements of the concentration and composition of nuclei for cirrus formation. P. Natl. Acad. Sci. U.S.A. 100, 14655-14660.

Ertel, H. 1942. Ein neuer hydrodynamischer Wirbelsatz. Meteorol. Z. 59, 277-281.

Flohn, H., Kapala, A., Knoche, H. R. and Mächel, H. 1992. Water vapor as an amplifier of the greenhouse effect: new aspects. Meteorol. Z., NF 1, 122-138.

Fusina, F., Spichtinger, P. and Lohmann, U. 2007. Impact of ice supersaturated regions and thin cirrus on radiation in the midlatitudes. $J$. Geophys. Res. 112, D24S14, doi:10.1029/2007JD008449.

Gabriel, A. and Peters, D. 2008. A diagnostic study of Rossby wave breaking events in the northern hemisphere. J. Meteor. Soc. Japan 86(5), 613-631.

Gierens, K., Schumann, U., Helten, M., Smit, H. and Marenco, A. 1999. A distribution law for relative humidity in the upper troposphere and lower stratosphere derived from three years of MOZAIC measurements. Ann. Geophys. 17, 1218-1226.

Gierens, K. 2003. On the transition between heterogeneous and homogeneous freezing. Atmos. Chem. Phys. 3, 437-446, http://www.atmoschem-phys.net/3/437/2003/.

Immler, F., Treffeisen, R., Engelbart, D., Krüger, K. and Schrems, O. 2008. Cirrus, contrails, and ice supersaturated regions in high pressure systems at northern mid latitudes. Atmos. Chem. Phys. 8, 1689-1699.

James, P. M. and Peters, D. 2002. The Lagrangian structure of ozone mini-holes and potential vorticity anomalies. Ann. Geophys. 20, 835-846.
Kaercher, B. and Lohmann, U. 2002. A Parameterization of cirrus cloud formation: homogeneous freezing including effects of aerosol size. $J$. Geophys. Res. 107, 4698, doi:10.1029/2001JD001429.

Kaercher, B. and Ström, J. 2003. The roles of dynamical variability and aerosols in cirrus cloud formation. Atmos. Chem. Phys. 3, 823-838.

Kaercher, B., Hendricks, J. and Lohmann, U. 2006. Physically-based parameterization of cirrus cloud formation for use in global atmospheric models. J. Geophys. Res. 111, D01205, doi:10.1029/2005JD006219.

Kaercher, B, Möhler, O., DeMott, P. J., Pechtl, S. and Yu, F. 2007. Insights into the role of soot aerosols in cirrus cloud formation. Atmos. Chem. Phys. 4203-4227.

Kirchner, I. and Peters, D. 2003. Modelling the wintertime response to upper tropospheric and lower stratospheric ozone anomalies over the North Atlantic and Europe. Ann. Geophys. 21, 2107-2118.

Koch, G., Wernli, H., Schwierz, C., Staehelin, J. and Peter, T. 2005. A composite study on the structure and formation of ozone miniholes and minihighs over Central Europe. Geophys. Res. Lett. 32, L12810, doi:10.1029/2004GL022062.

Koop, T. 2004. Homogeneous ice nucleation in water and aqueous solutions (Review Article). Z. Phys. Chem. 218, 1231-1258.

Koop, T., Luo, B., Tsias, A. and Peter, T. 2000. Water activity as the determinant for homogeneous ice nucleation in aqueous solutions. Nature 406, 611-614.

Krämer, M., Schiller, C., Afchine, A., Bauer, R., Gensch, I. and coauthors. 2009. Ice supersaturations and cirrus cloud crystal numbers. Atmos. Chem. Phys. 9, 3505-3522.

Lynch, D. K., Sassen, D., Starr, O'C. and Stephens, G. 2002. Cirrus. Oxford University Press, New York, 480 pp.

Mace, G. G., Benson, S. and Vernon, E. 2006. On the relationship between cirrus cloud occurrence and microphysical properties with the large-scale atmospheric state revealed by 6 years of continuous ground-based cloud radar data. J. Climate. 19(13), 32573278.

Murphy, D. M. and Koop, T. 2005. Review of the vapor pressures of ice and supercooled water for atmospheric applications. Quart. J. Royal Met. Soc. 131, 1539-1565.

Nakamura, M. and Plumb, R. A. 1994. The effects of flow asymmetry on the direction of Rossby wave breaking. J. Atmos. Sci. 51, 2031-2045.

Peter, T., Marcolli, C., Spichtinger, P., Corti, T., Baker, M. B. and co-authors. 2006. When dry air is too humid. Science 314(5804), 1399-1402.

Peters, D. and Waugh, D. W. 1996. Influence of barotropic shear on the poleward advection of upper-tropospheric air. J. Atmos. Sci. 53, 3013-3031.

Randel, W. J. and Stanford, J. L. 1985. The observed life cycle of a baroclinic instability. J. Atmos. Sci. 42(13), 1364-1373, doi:10.1175/15200469.

Sassen, K. and Campbell, J. R. 2001. A midlatitude cirrus cloud climatology from the facility for atmospheric remote sensing. Part I: macrophysical and synoptic properties. J. Atmos. Sci. 58, 481-496.

Simmons, A. J. and Hoskins, B. J. 1978. The life cycles of some nonlinear baroclinic waves. J. Atmos. Sci. 35, 414-432.

Simmons, A. J. and Hoskins, B. J. 1980. Barotropic influences on the growth and decay of nonlinear baroclinic waves. J. Atmos. Sci. 37, 1679-1684.

Sonntag, D. 1990. Important new values of the physical constants of 1986, vapour pressure formulations based on ITS-90, and psychrometer formulae. Z. f. Meteorologie. 40(5), 340-344. 
Spichtinger, P., Gierens, K., Leiterer, U. and Dier, H. 2003. Ice supersaturation in the tropopause region over Lindenberg, Germany. Meteorol. Z. 12, 143-156.

Spichtinger, P., Gierens, K. and Wernli, H. 2005a. A case study on the formation and evolution of ice supersaturation in the vicinity of a warm conveyor belt's outflow region. Atmos. Chem. Phys. 5, 973-987, SRef-ID: 1680-7324/acp/2005-5-973.

Spichtinger, P., Gierens, K. and Dörnbrack, A. 2005b. Formation of ice supersaturation by mesoscale gravity waves. Atmos. Chem.. Phys. 5, 1243-1255, SRef-ID: 1680-7324/acp/2005-5-973.

Spichtinger, P. and Gierens, K. M. 2009a. Modelling of cirrus clouds. Part 1a: model description and validation. Atmos. Chem. Phys. 9, 685-706.

Spichtinger, P. and Gierens, K. M. 2009b. Modelling of cirrus clouds. Part 1b: structuring cirrus clouds by dynamics. Atmos. Chem. Phys. 9, 707-719.

Spichtinger, P. and Gierens, K. M. 2009c. Modelling of cirrus clouds. Part 2: competition of different nucleation mechanisms. Atmos. Chem. Phys. 9, 2319-2334.

Thorncroft, C. D., Hoskins, B. J. and McIntyre, M. E. 1993. Two paradigms of baroclinic-wave life-cycle behavior. Quart. J. R. Met. Soc. 119, 17-55.
Tompkins, A. M., Gierens, K. and Rädel, G. 2007. Ice supersaturation in the ECMWF integrated forecast system. Quart. J. R. Met. Soc. 133, 53-63.

Vali, G. 1985. Atmospheric ice nucleation-a review. J. Rech. Atmos. 19, 105-115.

Vömel, H., David, D. E. and Smith, K. 2007. Accuracy of tropospheric and stratospheric water vapor measurements by the cryogenic frost point hygrometer: instrumental details and observations. J. Geophys. Res. 112, D08305, doi:10.1029/2006JD007224.

Wernli, H. and Davies, H. C. 1997. A Lagrangian-based analysis of extratropical cyclones, I: the method and some applications. $Q . J$. Roy. Meteorol. Soc. 123, 467-489.

WMO. 2006. Guide to Meteorological instruments and methods of observation, preliminary seventh edition, WMO-Nr. 8.

Zhang, Y., Macke, A. and Albers, F. 1999. Effect of crystal size spectrum and crystal shape on stratiform cirrus radiative forcing. Atmos. Res. 52, 59-75, doi:10.1016/ S0169-8095(99)00026-5.

Zülicke, Ch. and Peters, D. 2007. Parameterization of strong stratospheric inertia-gravity waves forced by poleward breaking Rossby waves. Mon. Wea. Rev. 136(1), 98-119, doi:10.1175/2007MWR2060.1. 